\title{
Maternal asthma, premature birth, and the risk of respiratory morbidity in schoolchildren in Merseyside
}

\author{
Y J Kelly, B J Brabin, P Milligan, D P Heaf, J Reid, M G Pearson
}

\begin{abstract}
Background - A study was carried out to analyse the impact of maternal asthma on the risk of preterm delivery and the contribution of preterm delivery to the development of childhood asthma.

Methods - Two cross sectional community studies of 1872 children (5-11 years) in 1991 and 3746 children in 1993 were performed. A respiratory health questionnaire was distributed throughout 15 schools in Merseyside and completed by the parents of the children.
\end{abstract}

Results - Asthmatic mothers were more likely to have a preterm delivery than nonasthmatic mothers (odds ratio (OR) 1.49; $95 \%$ CI $1 \cdot 10$ to $2 \cdot 02$ ). Smoking was a separate risk factor for preterm delivery (OR 1.35; 95\% CI $1 \cdot 10$ to $1 \cdot 65)$. Asthmatic mothers did not have an increased risk of delivering small, growth retarded babies. Maternal asthma, paternal asthma, and premature birth, in that order, increased the risk of later childhood respiratory morbidity (OR 3.13, 95\% CI $2 \cdot 36$ to $4 \cdot 16$; $2 \cdot 23,95 \%$ CI $1 \cdot 62$ to $3 \cdot 05 ; 1 \cdot 40,95 \%$ CI $1 \cdot 10$ to $1 \cdot 79)$. Conversely, babies who were small for gestational age appeared less likely to develop doctor diagnosed asthma or the symptom triad of cough, wheeze, and breathlessness in childhood, although this was not statistically significant (OR $0 \cdot 63,95 \%$ CI 0.28 to $1 \cdot 41$ ).

Conclusions - Maternal smoking during pregnancy and maternal asthma are independent risk factors associated with preterm delivery. Asthma in mothers predisposes to preterm delivery but not fetal growth retardation. Preterm birth, but not growth retardation, predisposes the child to the development of subsequent asthma.

(Thorax 1995;50:525-530)

Keywords: asthma, preterm delivery, maternal asthma, smoking, children.

In a study of children born in one week in $1970,{ }^{1}$ wheezing at the age of five was reported to be more common in those who were born prematurely or who were of low birthweight. There are a number of possible explanations for this; small, premature infants are more prone to respiratory illnesses in early life which can result in airways obstruction and impaired lung function. ${ }^{2}$ There is an effect of maternal smoking on preterm delivery, low birthweight, and infant lung function. ${ }^{3}$ Children of asthmatic mothers are at increased risk of atopic disease and bronchial hyperreactivity, ${ }^{45}$ and it has been suggested that maternal asthma may predispose to premature labour. ${ }^{67}$ Hyperactivity of uterine smooth muscle could occur in women with bronchial hyperresponsiveness and $\beta$ agonists might be beneficial in prolonging gestation. ${ }^{8}$ There is some evidence that asthmatic mothers not requiring inhaled $\beta$ agonist bronchodilators during pregnancy have a higher incidence of low birthweight babies. ${ }^{9}$ However, a recent controlled prospective study did not significantly associate use of inhaled bronchodilators with preterm births, low birthweight, or adverse perinatal outcome. ${ }^{10}$

These studies do not report on respiratory outcome in children for whom both perinatal outcome, parental history of asthma, and smoking during pregnancy are known. This paper is a further analysis of a study designed to collect information on environmental exposures and respiratory symptoms in primary schoolchildren for whom we had data on perinatal outcome (shown as prematurity and birthweight), as well as current respiratory symptoms, 5-11 years later. We have analysed the impact of maternal asthma on prematurity and birthweight and the subsequent effect of all of these factors on the development of respiratory symptoms in children.

\section{Methods}

\section{STUDY DESIGN}

A cross sectional survey to determine the prevalence of respiratory symptoms in primary schoolchildren (5-11 years) was performed between October and December 1991 in three communities in Merseyside. Briefly, in 1991 a parent-completed questionnaire was distributed to every alternate child on the class register in five schools in each of the three communities. All communities were recognised as having major housing and unemployment problems, and one of the areas was known to be exposed to increased levels of air pollution. The general data and detailed methods are reported elsewhere. ${ }^{11}$ This survey indicated a probable association between maternal asthma and preterm delivery. In the same months of 1993 a second survey of a larger sample which included all children in the same school population was performed, using the same questionnaire, but with additional questions relating to pregnancy, history of smoking, and maternal 
Table 1 Prevalence of preterm delivery in 1991 and 1993 in relation to parental asthma

\begin{tabular}{llc}
\hline & \multicolumn{2}{l}{ Prevalence of preterm delivery (\%) } \\
\cline { 2 - 3 } Survey group and year & Parent asthmatic & Parent non-asthmatic \\
\hline 1991 & $23 \cdot 7(28 / 118)$ & $14.0(220 / 1574)$ \\
$\quad$ Mother & $16.7(17 / 102)$ & $14 \cdot 1(220 / 1559)$ \\
Father & & \\
1993 & $19 \cdot 1(61 / 319)$ & $13.0(410 / 3158)$ \\
Mother & $14.7(34 / 232)$ & $13.2(405 / 3066)$ \\
Father & & \\
\hline
\end{tabular}

medication for asthma. The larger sample size in the second survey enabled the associations and statistical significance between maternal asthma and preterm delivery to be assessed in detail.

\section{QUESTIONNAIRE}

The questionnaire was adapted and modified from a questionnaire designed by Clifford et $a l .{ }^{12}$ It included questions on factors related to risk of preterm delivery including maternal and paternal socioeconomic factors, employment status, and smoking of either parent during the pregnancy or subsequently. The birthweight of the child was requested and preterm delivery was defined according to the parental response to the question "Was your baby born prematurely?" Several factors related to the risk of asthma in the children were requested, and included type of dwelling (carpets, dampness); type of heating; presence of furry pets in the home; type of infant feeding; family history of allergy; and exposure to air pollutants. Wheeze and dyspnoea were identified by the questions "Has your child ever had an attack of wheezing (by wheezing I mean noisy breathing and a whistling sound coming from the chest or throat)?" and "Has your child ever been either unexpectedly breathless at rest or more breathless than you would expect after exercise (by breathless I mean out of breath or puffed)?" The question used to identify abnormal cough was "Has your child ever seemed to cough (or get more coughs) than other children?" All parents were asked if their child had ever been diagnosed by a doctor as having asthma or bronchial asthma. Parental asthma was identified with the question "Does the child's mother or father suffer from asthma?" and maternal smoking during pregnancy with the question "Did the mother or father of this child smoke during the mother's pregnancy?"

Questionnaires were delivered to schools and surveys completed concurrently in South Sef- ton, Waterloo, Netherton, and Bootle (north and east of the Mersey estuary), and Wallasey (south of the Mersey estuary). Children returned questionnaires during the following two week period. Repeat visits to schools were made by a research worker for absentees. Ethical 음 approval for the study was given by the South $\underset{x}{ }$ Sefton ethical committee. Children were defined as low birthweight if $<2.5 \mathrm{~kg}$ at delivery and preterm according to the parental response to the prematurity question. Small for gest- $\frac{O}{\omega}$ ational age infants were those reported as full term babies whose birthweight was $<2.5 \mathrm{~kg}$.

\section{STRATIFIED ANALYSIS}

Contingency tables were analysed using hierarchical log linear modelling. Odds ratios cal- $\overrightarrow{\vec{x}}$ culated for the main effects of interest were of adjusted for confounders using logistic re- o gression. Potential confounders were of three of main types: socioeconomic, environmental, of and factors related to predisposition.

\section{Results}

In 1991 a total of 1872 questionnaires were $\vec{\theta}$ returned out of 2035 sent to parents (92\%). In the second survey in 1993 a total of 3746 . out of 4288 sent to parents were returned $(87 \%) ; 1093$ children were surveyed on both occasions. Of the 1991 respondents $97 \cdot 1 \% \stackrel{\text { ㅇ }}{2}$ answered the question on preterm delivery and $\stackrel{\square}{\square}$ 95.9\% provided their child's birthweight. In $\overline{\mathrm{o}}$ 1993 the figures were $97 \cdot 4 \%$ and $96 \cdot 8 \%$, respectively. Response rates for the main respiratory variables in 1991 were $89.5 \%$ (doctor diagnosed asthma), $85 \cdot 8 \%$ (wheezing), $86 \cdot 6 \%$ 을 (breathlessness), and $90 \cdot 1 \%$ (cough). Very similar response rates were observed for the 1993 survey. For parents who completed the questionnaire in both surveys the agreement be- of tween answers on prematurity and birthweight $₹$ were $97 \%$ and $98 \%$, respectively. The mean 은 difference in birthweights that did not match $D$ was small $(168 \mathrm{~g})$. The agreement for respiratory symptoms was doctor diagnosed $\mathrm{N}$ asthma $(93.1 \%)$, wheezing $(69.9 \%)$, breath- $\mathrm{N}$ lessness $(62 \cdot 1 \%)$, maternal asthma $(89 \cdot 7 \%)$, N and paternal asthma $(77 \cdot 8 \%)$.

\section{MATERNAL ASTHMA AND PRETERM BIRTH}

In both surveys there was a significant increase $T$ in reported preterm delivery associated with maternal but not paternal asthma (table 1).

Table 2 Prevalence of preterm, growth retarded, and full term deliveries in relation to parental asthmatic status (1993 survey)

\begin{tabular}{|c|c|c|c|c|c|c|c|c|c|}
\hline \multirow{3}{*}{ Parent } & \multicolumn{4}{|c|}{ Asthmatic parent } & & \multicolumn{4}{|c|}{ Non-asthmatic parent } \\
\hline & \multicolumn{2}{|l|}{ Full term } & \multicolumn{2}{|l|}{ Preterm } & & \multicolumn{2}{|l|}{ Full term } & \multicolumn{2}{|l|}{ Preterm } \\
\hline & $<2.5 \mathrm{~kg}^{*}$ & $\geqslant 2.5 \mathrm{~kg} \dagger$ & $<2.5 \mathrm{~kg}$ & $\geqslant 2.5 \mathrm{~kg}$ & & $<2.5 \mathrm{~kg}^{*}$ & $\geqslant 2.5 \mathrm{kgt}$ & $<2.5 \mathrm{~kg}$ & $\geqslant 2.5 \mathrm{~kg}$ \\
\hline $\begin{array}{l}\text { Mother } \\
{[n=317]}\end{array}$ & $\begin{array}{l}3 \\
(0.9)\end{array}$ & $\begin{array}{l}253 \\
(79 \cdot 8)\end{array}$ & $\begin{array}{l}24 \\
(7 \cdot 6)\end{array}$ & $\begin{array}{l}37 \\
(11 \cdot 7)\end{array}$ & {$[\mathrm{n}=3120]$} & $\begin{array}{l}58 \\
(1 \cdot 9)\end{array}$ & $\begin{array}{l}2657 \\
(85 \cdot 1)\end{array}$ & $\begin{array}{l}162 \\
(5 \cdot 3)\end{array}$ & $\begin{array}{l}243 \\
(7 \cdot 8)\end{array}$ \\
\hline $\begin{array}{l}\text { Father } \\
{[n=229]}\end{array}$ & $\begin{array}{l}2 \\
(0 \cdot 9)\end{array}$ & $\begin{array}{l}193 \\
(84 \cdot 3)\end{array}$ & $\begin{array}{l}13 \\
(5 \cdot 7)\end{array}$ & $\begin{array}{l}21 \\
(9 \cdot 2)\end{array}$ & {$[\mathrm{n}=3030]$} & $\begin{array}{l}54 \\
(1 \cdot 8)\end{array}$ & $\begin{array}{l}2573 \\
(84 \cdot 9)\end{array}$ & $\begin{array}{l}155 \\
(5 \cdot 1)\end{array}$ & $\begin{array}{l}247 \\
(8 \cdot 2)\end{array}$ \\
\hline
\end{tabular}

* Small for gestational age (full term and $<2.5 \mathrm{~kg}$ birthweight).

$\dagger$ Appropriate for gestational age (full term and $\geqslant 2.5 \mathrm{~kg}$ birthweight).

Numbers in parentheses are percentages. Associations among preterm delivery, low birthweight $(<2.5 \mathrm{~kg})$, paternal and maternal asthma were assessed by log linear analysis of the four-way table. The best fitting hierarchical model showed two significant associations: preterm birth and low birthweight ( $<<0 \cdot 001)$; maternal asthma and preterm birth $(p=0 \cdot 02)$. 
Table 3 Odds ratio for preterm delivery among mothers in relation to asthmatic status and cigarette smoke exposure during pregnancy

\begin{tabular}{lll}
\hline $\begin{array}{l}\text { Maternal asthmatic and } \\
\text { pregnancy smoking status }\end{array}$ & $\begin{array}{l}\text { Prevalence (\%) of } \\
\text { preterm delivery }\end{array}$ & $\begin{array}{l}\text { Unadjusted odds ratio* } \\
\text { (95\% CI) }\end{array}$ \\
\hline Asthmatic and smoker & 19.8 & $1.91(1.18$ to 3.06$)$ \\
Asthmatic and non-smoker & 17.5 & $1.63(1.07$ to 2.49) \\
Non-asthmatic and smoker & 15.3 & $1.39(1.11$ to 1.73$)$ \\
Non-asthmatic and non-smoker & 11.5 & \\
\hline
\end{tabular}

* Compared with non-asthmatic, non-smoking mothers.

Table 4 Adjusted odds ratios for preterm delivery from multiple logistic regression

\begin{tabular}{lll}
\hline Variable & Odds ratio & $95 \%$ confidence interval \\
\hline 1991 survey $(\mathrm{n}=1715)$ & & \\
$\quad$ Maternal asthma & 1.89 & 1.21 to 2.96 \\
Any smokers in household & 1.64 & 1.22 to 2.19 \\
1993 survey ( $\mathrm{n}=3403)$ & & \\
$\quad$ Maternal asthma & 1.49 & 1.10 to 2.02 \\
$\quad$ Mother smoking during pregnancy & 1.35 & 1.10 to 1.65 \\
\hline
\end{tabular}

Table 5 Prevalence of respiratory morbidity in children in relation to prematurity by parental asthmatic status (1993 survey)

\begin{tabular}{|c|c|c|}
\hline \multirow{2}{*}{$\begin{array}{l}\text { Parental asthmatic status and } \\
\text { childhood respiratory outcome }\end{array}$} & \multicolumn{2}{|l|}{ Birth category } \\
\hline & Full term & Preterm \\
\hline $\begin{array}{l}\text { Asthmatic mother: } \\
\text { Ever diagnosed asthma } \\
\text { Cough, wheeze, breathlessness } \\
\text { Asymptomatic }\end{array}$ & $\begin{array}{rr}41 \cdot 4 & (106 / 256) \\
17 \cdot 8 & (35 / 197) \\
49 \cdot 2 & (97 / 197)\end{array}$ & $\begin{array}{lr}45 \cdot 8 & (27 / 59) \\
16 \cdot 3 & (7 / 43) \\
53 \cdot 5 & (23 / 43)\end{array}$ \\
\hline $\begin{array}{l}\text { Non-asthmatic mother: } \\
\text { Ever diagnosed asthma } \\
\text { Cough, wheeze, breathlessness } \\
\text { Asymptomatic }\end{array}$ & $\begin{array}{rr}19 \cdot 0 & (513 / 2694) \\
5 \cdot 6 & (129 / 2299) \\
72 \cdot 6 & (1668 / 2299)\end{array}$ & $\begin{array}{l}26 \cdot 7(102 / 382) \\
10 \cdot 5(35 / 334) \\
63.2(211 / 334)\end{array}$ \\
\hline $\begin{array}{l}\text { Asthmatic father: } \\
\text { Ever diagnosed asthma } \\
\text { Cough, wheeze, breathlessness } \\
\text { Asymptomatic }\end{array}$ & $\begin{array}{ll}36.1 & (70 / 194) \\
13 \cdot 3 & (21 / 158) \\
52.5 & (83 / 158)\end{array}$ & $\begin{array}{rr}55.9 & (19 / 34) \\
25.0 & (5 / 24) \\
37.5 & (9 / 24)\end{array}$ \\
\hline $\begin{array}{l}\text { Non-asthmatic father: } \\
\text { Ever diagnosed asthma } \\
\text { Cough, wheeze, breathlessness } \\
\text { Asymptomatic }\end{array}$ & $\begin{array}{rr}19 \cdot 6 & (512 / 2607) \\
5 \cdot 9 & (130 / 2209) \\
70 \cdot 1 & (1548 / 2209)\end{array}$ & $\begin{array}{lr}24 \cdot 9 & (99 / 397) \\
10 \cdot 3 & (34 / 331) \\
66 \cdot 2 & (219 / 331)\end{array}$ \\
\hline
\end{tabular}

Ever diagnosed asthma = asthma diagnosed by a doctor; cough $=$ excess cough in previous 12 months; wheeze $=$ attack of wheezing at any time; breathlessness $=$ attack of breathlessness at any time.

Table 6 Prevalence of respiratory morbidity in children in relation to fetal growth retardation by parental asthma status (1993 survey)

\begin{tabular}{|c|c|c|}
\hline \multirow{2}{*}{$\begin{array}{l}\text { Parental asthmatic status and } \\
\text { childhood respiratory outcome }\end{array}$} & \multicolumn{2}{|l|}{ Birth category } \\
\hline & Full term $(\geqslant 2.5 \mathrm{~kg})$ & Full term $(<2.5 \mathrm{~kg})^{*}$ \\
\hline $\begin{array}{l}\text { Asthmatic mother: } \\
\text { Ever diagnosed asthma } \\
\text { Cough, wheeze, breathlessness } \\
\text { Asymptomatic }\end{array}$ & $\begin{array}{lr}40 \cdot 1 & (103 / 253) \\
17 \cdot 9 & (35 / 196) \\
49 \cdot 5 & (97 / 196)\end{array}$ & $\begin{array}{ll}0.0 & (0 / 3) \\
0.0 & (0 / 1) \\
0.0 & (0 / 1)\end{array}$ \\
\hline $\begin{array}{l}\text { Non-asthmatic mother: } \\
\text { Ever diagnosed asthma } \\
\text { Cough, wheeze, breathlessness } \\
\text { Asymptomatic }\end{array}$ & $\begin{array}{rr}19 \cdot 2 & (506 / 2636) \\
5 \cdot 7 & (128 / 2251) \\
72 \cdot 5 & (1633 / 2251)\end{array}$ & $\begin{array}{rr}13.8 & (8 / 58) \\
2.1 & (1 / 48) \\
72.9 & (35 / 48)\end{array}$ \\
\hline $\begin{array}{l}\text { Asthmatic father: } \\
\text { Ever diagnosed asthma } \\
\text { Cough, wheeze, breathlessness } \\
\text { Asymptomatic }\end{array}$ & $\begin{array}{ll}36 \cdot 5 & (70 / 192) \\
13 \cdot 4 & (21 / 157) \\
52 \cdot 2 & (82 / 157)\end{array}$ & $\begin{array}{rr}0.0 & (0 / 2) \\
0.0 & (0 / 1) \\
100 \cdot 0 & (1 / 1)\end{array}$ \\
\hline $\begin{array}{l}\text { Non-asthmatic father: } \\
\text { Ever diagnosed asthma } \\
\text { Cough, wheeze, breathlessness } \\
\text { Asymptomatic }\end{array}$ & $\begin{array}{rr}19 \cdot 8 & (505 / 2553) \\
6 \cdot 0 & (129 / 2164) \\
72 \cdot 4 & (1566 / 2164)\end{array}$ & $\begin{array}{rr}13 \cdot 0 & (7 / 54) \\
2 \cdot 2 & (1 / 45) \\
71 \cdot 1 & (32 / 45)\end{array}$ \\
\hline
\end{tabular}

* Small for gestational age.

Ever diagnosed asthma = asthma diagnosed by a doctor; cough $=$ excess cough in previous 12 months; wheeze = attack of wheezing at any time; breathlessness = attack of breathlessness at any time.

The prevalence of preterm delivery among the 2652 children surveyed in 1993 but not in 1991 was $17 \cdot 1 \%$ for asthmatic and $13.0 \%$ for non-asthmatic mothers. Children in the 1993 survey were separated into birth categories de- termined by birthweight $(<2.5 \mathrm{~kg}$ or $\geqslant 2.5 \mathrm{~kg})$ and prematurity status. Significantly more preterm babies were born to asthmatic mothers (table 2), but amongst these preterm babies asthma did not significantly increase the risk of low birthweight $(<2.5 \mathrm{~kg})$. The mean (SD) birthweight of preterm babies over $2.5 \mathrm{~kg}$ was $2.62(0.64) \mathrm{kg}$ which corresponds to a 50th percentile at 34.5 weeks gestation on the Tanner and Thomson growth charts. ${ }^{13}$ No difference in prevalence of growth retarded babies (full term gestation and $<2.5 \mathrm{~kg}$ ) was observed in relation to parental asthmatic status. The mean (SD) birthweights for growth retarded full term and normal full term infants were $2.25(0.19) \mathrm{kg}$ and $3.47(0.46) \mathrm{kg}$, respectively.

Maternal asthma and smoking during pregnancy each increased the risk of preterm delivery. Table 3 shows the unadjusted odds ratios for the various categories of mothers. Asthmatic mothers who smoked were at the highest risk. Logistic regression was used to calculate adjusted odds ratios for the effects of smoking and asthma. This was done separately for the 1991 and 1993 surveys (table 4). In both 1991 and 1993 maternal asthma was the predominant risk factor for preterm delivery. "Any smokers in the household" was the only significant risk factor identified for the 1991 model. The 1993 survey showed that it was maternal smoking during pregnancy, rather than paternal smoking or other smokers in the household (that is, passive smoking), which was directly associated with increased risk of preterm delivery. There was no statistical interaction between maternal asthma and smoking, indicating that they had separate effects. Other health problems, allergies, and paternal unemployment - though significant when considered in isolation - did not have odds ratios significantly different from unity after adjustment for known confounders. Adding any more predictors did not significantly improve the models nor change the parameter estimates. Information on maternal parity was not available on the questionnaire and could not be added to the model. Maternal smoking during pregnancy was not associated with increased risk of delivering a baby that was small for gestational age (odds ratio (OR) $1 \cdot 63,95 \% \mathrm{CI}$ 0.97 to $2 \cdot 73)$.

PARENTAL ASTHMA, BIRTHWEIGHT, PREMATURITY, AND LATER CHILDHOOD RESPIRATORY MORBIDITY

Adjusted odds ratios were estimated using logistic regression analysis of the data in table 5 and showed an effect of maternal asthma (OR $3 \cdot 13 ; 95 \%$ CI 2.36 to $4 \cdot 16$ ); paternal asthma (OR $2.23 ; 95 \%$ CI 1.62 to 3.05 ), and preterm birth (OR $1.40 ; 95 \%$ CI 1.10 to 1.79 ) on increasing the risk of developing ever diagnosed asthma. Using the definition of asthma as the presence of cough, wheezing, and breathlessness, the analysis showed a similar pattern: maternal asthma (OR 3.30; 95\% CI $2 \cdot 17$ to 5.03), paternal asthma (OR $1 \cdot 94 ; 95 \%$ CI $1 \cdot 16$ to $3 \cdot 25$ ), premature birth (OR $1 \cdot 89 ; 95 \% \mathrm{CI}$ 1.29 to $2 \cdot 76$ ). A number of environmental, 
socioeconomic, and predisposing factors contribute to the risk of respiratory morbidity in children. These include other allergies and health problems, young age, sex (boy), parental unemployment, household dampness, rented accommodation, and geographical area. Adjusting for each of these variables the odds ratio for developing ever diagnosed asthma in preterm babies was 1.41 (95\% CI 1.06 to 1.87), and for developing cough, wheeze, and breathlessness $1 \cdot 82$ (95\% CI $1 \cdot 15$ to $2 \cdot 88$ ). Smoking during pregnancy or passive smoking was not associated with any of the respiratory outcome variables in univariate tests in the 1993 data. It was therefore not an important confounder of the relationship between preterm birth and later respiratory symptoms.

Table 6 shows that infants in our survey born small for gestational age to either asthmatic or non-asthmatic parents were at reduced risk of developing asthmatic respiratory symptoms compared with full term normal birthweight babies. This difference did not reach statistical significance, the odds ratio for developing ever diagnosed asthma being 0.63 (95\% CI 0.28 to 1.41 ) and for developing cough, wheeze, and breathlessness 0.37 (95\% CI 0.05 to $2 \cdot 73$ ). These findings are of interest as the reduction in risk was consistent in the different groups and contrasted with the results for preterm infants.

\section{Discussion}

\section{QUESTIONNAIRE}

Studies which rely on self-administered questionnaires are limited by the reliability and validity of the instruments used. Similar questionnaires have been shown to yield reproducible answers, ${ }^{14}$ although the National Child Development Study found that lifelong reports of asthma and reports over the previous year did not show good agreement. ${ }^{15}$ The validity of the survey is dependent on the response rate, and our high compliance figures of $92 \%$ and $87 \%$ compare favourably with other surveys, ${ }^{12}$ and reduce the effects of bias. Over $95 \%$ of our respondents answered the key questions relating to preterm delivery and birthweight.

For all the main respiratory symptom variables response rates were over $85 \%$. The measure of agreement for important measures in those who completed both surveys was generally good, although it was only $62 \cdot 1 \%$ for breathlessness. Ascertainment of prematurity by the question "Was your baby born prematurely?" is dependent on the mother's knowledge and understanding of gestational age at delivery, which may have been explained in a number of ways by the attending doctor or nurse. The validity of the answers is supported by the observation that the mean birthweight of babies above $2.5 \mathrm{~kg}$ and reported as preterm by the mother was $2 \cdot 62 \mathrm{~kg}$. This corresponds to the 50th percentile at 34.5 weeks gestation on the Tanner and Thomson growth charts. ${ }^{13}$ Only four preterm infants were above the 97th centile for birthweight at 37 weeks gestation. This distribution of birthweights for the pre- term group is comparable to reference percentiles for premature babies and supports the validity of parental recognition of preterm delivery. The prevalence of reported preterm delivery was $14 \%$ in the 1991 survey and $13 \%$ in the 1993 survey. Both these figures are appreciably higher than previous surveys using prospective data. A stronger case for the causality of the associations would be demonstrated if the validity of the preterm delivery data was confirmed against original birth registers. Current work in this study population is examining this information.

MATERNAL ASTHMA, SMOKING, AND PRETERM DELIVERY

Biological and obstetric factors can play an important part in determining gestational duration. A recent meta-analysis identified 43 factors associated with preterm delivery, ${ }^{16}$ but did not mention maternal asthma as a significant risk factor. Our analysis indicates a significant association between maternal asthma and preterm birth but, amongst preterm births, asthma does not increase the risk of low birthweight. This suggests that the effect of maternal asthma is primarily to shorten gestation to $34-37$ weeks rather than leading to very preterm delivery. The regression analysis which controlled for socioeconomic factors identified maternal asthma in both the 1991 and 1993 surveys as a risk factor for preterm delivery. Hypotheses to explain the association of maternal asthma and preterm delivery remain to be elucidated. An attractive theory is that of uterine smooth muscle hyperreactivity in women with bronchial hyperresponsiveness. The effect of $\beta$ agonists in inhibiting labour supports this hypothesis, and asthmatic patients not using $\beta$ agonist bronchodilators during pregnancy have been reported to have a higher incidence of low birthweight babies. ${ }^{9}$ Our data cannot address issues such as whether it is the severity of asthma or its treatment or control that is important.

The 1991 survey showed smokers in the household as a significant factor in increasing risk of preterm delivery. The greater detail on parental smoking collected in 1993 showed that maternal smoking during pregnancy was the important risk factor and not the passive effects of paternal smoking. Maternal asthma and maternal smoking appear to have independent and separate effects on increasing the incidence for prematurity. There is a large amount of literature on maternal smoking as an adverse factor on intrauterine growth (with birthweight reductions of up to $200 \mathrm{~g}$ ) and gestational duration. ${ }^{17}$ Previous studies have suggested that the effect of passive smoking on mean birthweight was $2-10$ times less than that of active smoking. ${ }^{18}$ Maternal smoking could cause preterm delivery through several mechanisms. Nicotine may result in an increase in maternal catecholamines and consequent uterine vasoconstriction. ${ }^{19}$

Maternal smoking was not associated with an increased risk of delivering a small for dates baby although the confidence interval for the 
odds ratio was close to significance $(0.97$ to $2 \cdot 73$ ). Many women do give up smoking in early pregnancy and do not consider themselves to have smoked during pregnancy when subsequently questioned. The question asked could not separate out this group and this question should be addressed to exclude possible confounding.

PREMATURE BIRTH AND CHILDHOOD ASTHMA While it is well established that children who survive bronchopulmonary dysplasia have poor airway function at school age, the long term outcome for preterm infants who do not develop bronchopulmonary dysplasia has been little studied. This is particularly the case for preterm infants who are born with birthweights greater than $2.5 \mathrm{~kg}$. Our analysis indicates that preterm, but not low birthweight, babies are at particular risk for developing childhood asthma. Of preterm babies born to asthmatic parents almost half have been diagnosed as asthmatic at some time by a doctor. Asthma diagnosed by a doctor at some time could significantly overstate the current problem so we also defined a group of children with the symptom triad of cough, wheeze, and breathlessness on the grounds that the occurrence of all three together was most likely to be asthma. This symptom triad is also highly significantly associated with having been born prematurely, although the absolute risk is about half the genetic risk from having asthmatic parents.

We observed that the risk of asthma (doctor diagnosed or cough, wheeze, and breathlessness) was greater for premature babies. Babies born at full term but who were less than $2.5 \mathrm{~kg}$ - that is, small for gestational age - were less likely than either full term normal weight or preterm babies to develop the symptom triad of cough, wheeze, and breathlessness or doctor diagnosed asthma. This did not reach statistical significance and the percentage of asymptomatic children is similar to that in children born appropriate for gestational age. Nevertheless, this observation may be worth studying in a larger cohort. Could it be that growth retardation in utero in some way protects against asthma?

The relationship of prenatal and early postnatal events to lung function and airways responsiveness in schoolchildren has been studied prospectively for infants with birthweights less than $2000 \mathrm{~g} .{ }^{2021}$ In these studies a reduction in airway function was observed in low birthweight children which was associated with cough but not wheeze. More recent research indicates that birthweight is related to lung size and methacholine responsiveness, and that prematurity and smoking during pregnancy appear to diminish airway size and increase the likelihood of exercise-induced bronchospasm or of asthma diagnosis. ${ }^{22-24} \mathrm{~A}$ re-analysis controlling for confounding factors of the British National Birth Cohort of children born in one week of 1970 also confirms the original observations of Golding and Butler implicating low birthweight in the aetiology of childhood wheezing. ${ }^{25} 26$
Studies relating passive smoking, low birthweight, and prematurity have been reviewed recently ${ }^{19}$ but the interrelationships of maternal asthma, active versus passive smoking by the parents, prematurity, and birthweight have not been systematically studied. Thus, if maternal asthma leads to prematurity and also influences the development of asthma, it is likely that univariate analysis will show prematurity associated with childhood asthma. Our data show that prematurity remains important even when the parental asthma is controlled, and also that it is the prematurity that is relevant regardless of birthweight.

A recent review of the literature ${ }^{19}$ cites 13 references that implicate smoking in pregnancy as a factor in causing wheezing illness in children. Our data suggest that paternal smoking (passive to the unborn child) is not significant after adjusting for maternal smoking. This is probably because maternal and paternal smoking incidence is highly correlated. Thus, passive smoking may be relatively unimportant and future studies should concentrate on maternal smoking. Active smoking results in nicotine and other vasoactive substances reaching the circulation which could affect the fetus.

Chan et al have suggested a model of the aetiology of chronic respiratory morbidity in childhood based on birthweight, maternal smoking, genetic, and environmental factors. ${ }^{2021}$ They were unable to determine the relative importance of these factors because of the small size of their study. Analysis of our more extensive data suggests that several different pathways are involved in the development of recurrent cough and wheeze in childhood. Maternal asthma is associated with premature birth which is compounded if the mother smokes during pregnancy. Premature birth is associated with an increased risk of childhood wheezing and breathlessness, whether or not the parents are asthmatic. Maternal asthma is also associated with recurrent respiratory symptoms in children independently of whether the child is born preterm. Thus, it seems that there are several pathways by which asthma evolves.

Our results indicate the importance of preterm delivery in predisposing to recurrent cough and wheeze in children. If this is confirmed then it should be possible to target particular groups of mothers or preterm babies for intervention studies testing hypotheses related to causation. For example, premature babies of asthmatic mothers are at very high risk of childhood symptoms and would permit smaller longitudinal studies of asthma causation than would otherwise be possible. These are the obvious target groups upon which to test the effectiveness of interventions in the future.

The questionnaire format was designed by Mr Ken Jones of the medical illustration unit of the Liverpool School of Tropical Medicine. We wish to thank Mrs Wanda Russell of the Epidemiology and Statistics Unit. Several people have supported demiology and Statistics Unit. Several people have supported and advised on the project since its inception. We are especially
grateful to Fr Michael de Felice, the headteachers of schools surveyed, health visitors and school nurses who assisted with the surveys, Dr H Klenka and the staff of Sefton and Wirral Environmental Health Departments. This study was made possible by grants from the Sefton Health Authority and Sefton 
Metropolitan Borough Council. Dr Paul Milligan gratefully acknowledges support from the Wellcome Trust.

1 Golding J, Butler NR. Wheezing and stress. In: Butler NR, Golding J, eds. From birth to five: a study of health and behaviour in British five year olds. Oxford: Pergamon Press, 1986:87-100.

2 Shaheen SO, Barker DJP. Early lung growth and chronic airflow obstruction. Thorax 1994;49:533-6.

3 Marsh MJ, Fox GF, Ingram D, Milner AD. The effect of maternal smoking during pregnancy on infant lung
function, growth and development. Proceedings of British Paediatric Association Annual Meeting 1994;66:28.

4 Bertrand JM, Riley SP, Popkin J, Coates AL. The longterm pulmonary sequelae of prematurity; the role of familial airway hyperreactivity and respiratory distress syndrome. $N$ Engl $\mathcal{f}$ Med 1985;312:742-5.

5 Cookson WDCM, Young RP, Sandford AJ, Moffatt MF, Shirakawa T, Sharp PA, et al. Maternal inheritance of atopic IgE responsiveness on chromosome 11q. Lancet atopic IgE respo

6 Doncatte JT, Bracken MB. Possible role of asthma in the risk of pre-term labor and delivery. Epidemiology 1993;4: 143-50.

7 Parlow JH, Montgomery D, Morgan MA, Towers CV, Porto M. Severity of asthma and perinatal outcome. Am $\mathcal{F}$ Obstet Gynecol 1992;167:963-7.

8 Shatz M, Zeiger RS, Hoffman CP. Intrauterine growth is related to gestational pulmonary function in pregnant asthmatic women. Chest 1990;98:389-92.

9 Lao TT, Huangslung M. Labor and delivery in mothers with asthma. Eur f Obstet Gynaecol Reprod Biol 1990;35: 183-90.

10 Shatz M, Zeiger AS, Handin KM, Hoffman CP, Forsythe AB, Chilingam LM, et al. The safety of inhaled betaagonist bronchodilators during pregnancy. $f$ Allergy Clin Immunol 1988;83:686-95.

11 Brabin B, Smith M, Milligan P, Benjamin C, Dunne E, Pearson MG. Respiratory morbidity in Merseyside schoolchildren exposed to coal dust and air pollution. Arch Dis Child 1994;70:305-12.

12 Clifford RD, Radford M, Howell JB, Holgate ST. Prevalence of respiratory symptoms among 7 and 11 year old schoolchildren and association with asthma. Arch Dis Child 1989; 64:118-25.

13 Tanner JM, Thomson AM. Standards for birthweights of gestation periods from 32 to 42 weeks allowing for maternal height and weight. Arch Dis Child 1970;46:566-75.

14 Cunningham J, Fay ME, Dockery DW, Speizer FE. Re-

liability of questionnaire reporting of early childhood health status, family history of respiratory illness and exposure to second-hand smoke. Am $\mathcal{f}$ Respir Crit Care Med 1994;149:A369.

15 Anderson HR, Pottier AC, Strachan DP. Asthma from birth to age 23: incidence and relation to prior and concurren atopic disease. Thorax 1992;47:537-42.

16 Kramer MS. Determination of low birthweight: MS. Determination of low bir thwigh: odological assessment and meta-analysis. Bull WHO 1987 ;

17 Kramer MS, Sasportas C. Determinants of intrauterine growth and gestational duration. A critical bibliography 1970-1984. World Health Organisation, 1985: Nut/85.10:90-96.

18 Fortier I, Marcoux S, Brisson J. Passive smoking during pregnancy and the risk of delivering a small-for-gestational-age infant. Am ₹ Epidemiol 1994;139:294-301.

19 Quigley ME. Effects of maternal smoking on increasing Catecholamines and foetal heart rates. Am $¥$ Obstet Gynecol 1979;133:685-90.

20 Chan KN, Noble-Jamieson CM, Elliman CJ, Bryan EM, Silverman $M$. Lung function in children of low birthweights. Arch Dis Child 1989;64:1284-93.

21 Chan KN, Elliman A, Bryan EM, Silverman M. Respiratory symptoms in children of low birthweight. Arch Dis Child 1989;64:1294-304.

22 Demisse $K$, Ernst $P$, Becklake MR, Joseph L Relationship of prenatal and early postnatal events to lung function of prenatal and early postnatal events to lung function and airways responsiveness in sch

23 Cunningham J, Dockery DW, Speizer FE. Maternal smoking during pregnancy as a predictor of lung function in children. Am F Epidemiol 1994;139:1139-52.

24 Helms PJ. Lung growth: implications for the developmen of disease. Thorax 1994;49:440-1.

25 Britton JR, Lewis S, Pavard I, Richards K, Knox A, Richards $\mathrm{D}$, et al. The influence of environmental factors on the onset and prognosis of respiratory disease in children and adults. In: Bronchitis $V$, Postma DS, Gerritsen J, eds. Assen: Van Gorcum Press, 1994.

26 Lewis S, Richards D, Bynner J, Butler N, Britton J. Th aetiology of wheezing illness in childhood and adolescence; a prospective study of the independent effects of passive smoking birthweight, maternal age and socioeconomic status. Am $₹$ Respir Crit Care Med 1994;149:A911. 